Author(s): Haarahiltunen, Antti \& Savin, Hele \& Yli-Koski, Marko \& Talvitie, Heli \& Sinkkonen, Juha

Title:

\title{
Modeling phosphorus diffusion gettering of iron in single crystal silicon
}

Year: $\quad 2009$

Version: Final published version

\section{Please cite the original version:}

Haarahiltunen, Antti \& Savin, Hele \& Yli-Koski, Marko \& Talvitie, Heli \& Sinkkonen, Juha. 2009. Modeling phosphorus diffusion gettering of iron in single crystal silicon. Journal of Applied Physics. P. 4. 0021-8979 (printed). DOI: 10.1063/1.3068337

Note:

Copyright 2009 American Institute of Physics. This article may be downloaded for personal use only. Any other use requires prior permission of the author and the American Institute of Physics.

http://scitation.aip.org/content/aip/journal/jap

All material supplied via Aaltodoc is protected by copyright and other intellectual property rights, and duplication or sale of all or part of any of the repository collections is not permitted, except that material may be duplicated by you for your research use or educational purposes in electronic or print form. You must obtain permission for any other use. Electronic or print copies may not be offered, whether for sale or otherwise to anyone who is not an authorised user. 


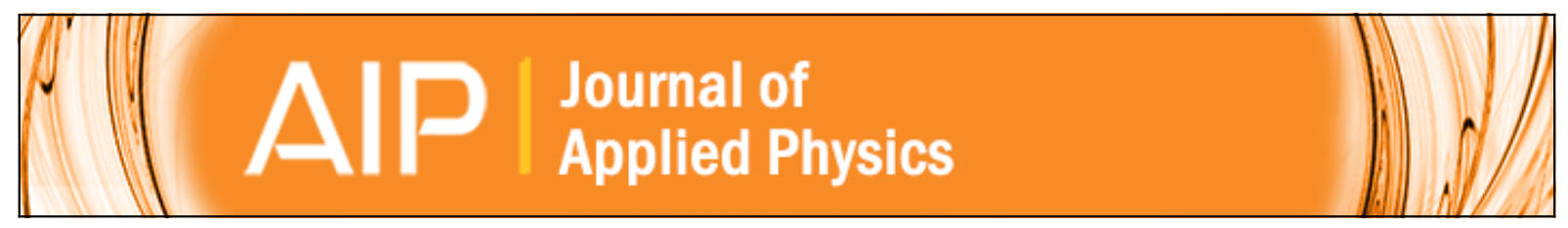

\section{Modeling phosphorus diffusion gettering of iron in single crystal silicon}

A. Haarahiltunen, H. Savin, M. Yli-Koski, H. Talvitie, and J. Sinkkonen

Citation: Journal of Applied Physics 105, 023510 (2009); doi: 10.1063/1.3068337

View online: http://dx.doi.org/10.1063/1.3068337

View Table of Contents: http://scitation.aip.org/content/aip/journal/jap/105/2?ver=pdfcov

Published by the AIP Publishing

\section{Articles you may be interested in}

Main defect reactions behind phosphorus diffusion gettering of iron

J. Appl. Phys. 116, 244503 (2014); 10.1063/1.4904961

Competitive gettering of iron in silicon photovoltaics: Oxide precipitates versus phosphorus diffusion

J. Appl. Phys. 116, 053514 (2014); 10.1063/1.4892015

Phosphorus and boron diffusion gettering of iron in monocrystalline silicon

J. Appl. Phys. 109, 093505 (2011); 10.1063/1.3582086

Modeling boron diffusion gettering of iron in silicon solar cells

Appl. Phys. Lett. 92, 021902 (2008); 10.1063/1.2833698

Experimental evidence for the presence of segregation and relaxation gettering of iron in polycrystalline silicon layers on silicon

Appl. Phys. Lett. 85, 4472 (2004); 10.1063/1.1819512

You don't

still use this

cell phone

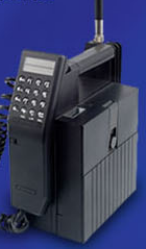

or this computer

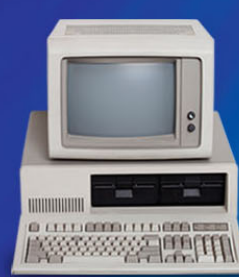

Why are you

still using an

AFM designed in the 80 's?
It is time to upgrade your AFM

Minimum \$20,000 trade-in discount for purchases before August 31st

Asylum Research is today's technology leader in AFM

dropmyoldAFM@oxinst.com

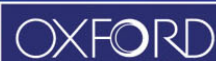




\title{
Modeling phosphorus diffusion gettering of iron in single crystal silicon
}

\author{
A. Haarahiltunen, ${ }^{a)}$ H. Savin, M. Yli-Koski, H. Talvitie, and J. Sinkkonen \\ Helsinki University of Technology, P.O. Box 3500, Helsinki FI-02015 TKK, Finland
}

(Received 5 July 2008; accepted 8 December 2008; published online 21 January 2009)

\begin{abstract}
We propose a quantitative model for phosphorus diffusion gettering (PDG) of iron in silicon, which is based on a special fitting procedure to experimental data. We discuss the possibilities of the underlying physics of the segregation coefficient. Finally, we show that the proposed PDG model allows quantitative analysis of gettering efficiency of iron at various processing conditions. (C) 2009 American Institute of Physics. [DOI: 10.1063/1.3068337]
\end{abstract}

\section{INTRODUCTION}

Phosphorus diffusion gettering (PDG) is widely acknowledged as an effective technique to remove detrimental transition metal contamination in silicon technology. In $p$-type silicon solar cell process, PDG is naturally included in the process to produce the phosphorus doped emitter. However, the gettering mechanism during PDG remains ambiguous and so far no quantitative model for PDG of iron has been presented despite the enormous experimental and theoretical studies on iron in silicon. Therefore, it is difficult to select the annealing conditions for the optimal gettering efficiency during device fabrication. The main problem in quantitative modeling of PDG of iron is uncertainty of physical model for the segregation coefficient to phosphorus doped layer. For instance, Istratov et al. assumed the segregation coefficient of iron in $n$-Si to equal the segregation coefficient of iron in equally doped $p$-Si. ${ }^{1}$ Seibt et al. used the properties of cobalt to simulate segregation of iron to phosphorus doped layer. $^{2}$

Indeed, there is lack of direct experimental data for iron during PDG as it is difficult to measure low concentrations of iron in $n$-type silicon. Clearly, the published secondary ion mass spectrometry (SIMS) results for iron during PDG are difficult to use in fitting as the SIMS results reflect a nonequilibrium iron distribution due to segregation to phosphorus layer and precipitation to wafer surfaces during cooling down. Moreover, a poor sensitivity of SIMS does not allow a real detection of gettering time dependency, i.e., it is impossible to detect the change in bulk iron concentration from $10^{12}$ to $10^{11} \mathrm{~cm}^{-3}$ by measuring high iron concentrations in the phosphorus layer. Our opinion is that quantitative simulations have to rely on the experimental data measured in the bulk ( $p$-Si).

In this paper, we describe a general method to determine the segregation coefficient of iron from the PDG experiments. We use the experimental data of Nadahara et $a l^{3}$ and Shabani et $a l^{4}{ }^{4}$ for fitting the model of iron solubility in highly phosphorus doped silicon. We then discuss the physical background of the iron solubility model to highly phosphorus doped wafers in which reactions of (i) vacancies with interstitial iron and (ii) substitutional iron with phosphorus

${ }^{a)}$ Electronic mail: antti.haarahiltunen@tkk.fi. are taken into account. Finally, we compare the simulations and experimental results in gettering processes with various times and temperatures.

\section{FITTING OF SEGREGATION COEFFICIENT}

Segregation of iron to heavily phosphorus doped region is induced by the difference in solubility inside a wafer. We define the segregation coefficient for iron as the relation between solubility in heavily doped phosphorus layer $S_{\mathrm{P}}(x)$ and solubility in low-doped boron substrate $S_{\mathrm{B}}$,

$$
k_{\text {seg }}(x)=\frac{S_{\mathrm{P}}(x)}{S_{\mathrm{B}}} .
$$

As the solubility of iron depends on the phosphorus concentration, segregation coefficient becomes a function of distance from the wafer surface. Note that the definition for the segregation coefficient in PDG experiments is not always consistent; for instance, Shabani et al. $^{4}$ defined it as the relation between iron concentration in the bulk $p$-Si before and after PDG anneal. Therefore, special care should be placed on comparison of the results obtained by different authors based on the definition that has been used.

We use the following approach to obtain the segregation coefficient for iron in phosphorus layer during PDG. First we assume constant supersaturation, i.e., relation between the dissolved iron concentration and solid solubility of iron, which is valid under steady state conditions. Second, from the conservation of mass it follows that the total iron concentration within the sample must remain constant initially and after gettering anneal. When iron is initially homogeneously distributed throughout the wafer thickness, we get

$$
\mathrm{Fe}_{\text {init }} T_{w}=\int_{0}^{x_{d}} k_{\text {seg }}(x) \mathrm{Fe}_{\text {bulk }} d x+\left(T_{w}-x_{d}\right) \mathrm{Fe}_{\text {bulk }},
$$

where $\mathrm{Fe}_{\text {init }}$ is the initial iron concentration, $\mathrm{Fe}_{\text {bulk }}$ is the iron concentration in the bulk after gettering anneal, $T_{w}$ is the wafer thickness, and $x_{d}$ is the depth of the phosphorus diffusion junction. From Eq. (2), we get easily the following:

$$
\int_{0}^{x_{d}} k_{\mathrm{seg}}(x) d x=x_{d}+\left(\frac{\mathrm{Fe}_{\text {init }}}{\mathrm{Fe}_{\text {bulk }}}-1\right) T_{w} .
$$

Using Eq. (3) we can fit the segregation coefficient to experimental data as all the other parameters are known. We use 
for the fitting the data published in Refs. 3 and 4, in which the PDG efficiency has been studied at various temperatures and times by measuring iron concentration in the bulk before and after gettering anneal with known phosphorus profiles.

Diffusion of high concentration of phosphorus in silicon follows the so-called kink and tail profile, which can be simulated quite accurately using the model suggested by Benzen et al. ${ }^{5}$ In this model phosphorus diffuses mainly via self-interstitial mechanism at low concentrations while at high phosphorus concentration diffusivity is associated with doubly negative vacancies. Above solid solubility of phosphorus, the diffusivity decreases due to the formation of phosphorus clusters; however, this has only a minor impact on simulation of phosphorus diffusion. We adopt this model for our simulations for phosphorus diffusion. The time dependency of phosphorus profiles was obtained by fitting the surface concentration of phosphorus to measured SIMS profiles $^{3,4}$ at single annealing time, which is a valid approach according to Ref. 5. The numerical algorithm, which was used to calculate iron diffusion and segregation, can be found from Ref. 6.

\section{MODEL FOR SEGREGATION COEFFICIENT}

We could use in Eq. (3) a purely empirical form for the segregation coefficient. However, here we want to discuss one relatively simple possibility for the dependence of segregation coefficient on phosphorus doping that we then use later in our simulations.

It is well known that interstitial iron in $p$-type silicon is a single positively charged $\mathrm{Fe}$ ion $\left(\mathrm{Fe}_{i}^{+}\right)$. In heavily $p$-doped silicon the solubility of iron is increased due to Fermi-level effect and the pairing reaction of positively charged $\mathrm{Fe}_{i}^{+}$and negatively charged boron atoms $\left(\mathrm{B}^{-}\right)$. In $n$-type silicon there is not a similar model for the enhanced solubility as $\mathrm{Fe}_{i}$ has a neutral charge state making pair formation with ionized phosphorus unlikely. ${ }^{7}$ Moreover, recent calculations based on first-principles theory suggest that interstitial iron is unable to create a vacancy to become substitutional. However, if there are pre-existing vacancies present in silicon, interstitial iron can readily interact with them and become substitutional. ${ }^{8}$ The previously mentioned model for phosphorus diffusion is based on the assumption of vacancy dominated diffusion in highly phosphorus doped region. ${ }^{5}$ Thus, in heavily $n$-doped region, we can write a reaction

$$
V^{--}+\mathrm{Fe}_{i} \leftrightarrow \mathrm{Fe}_{s}^{-}+e,
$$

where doubly charged vacancies interact with interstitial iron forming substitutional iron $\mathrm{Fe}_{s}$. We use $K_{\text {eq1 }}$ to describe the equilibrium constant of this reaction. The substitutional iron that is formed in reaction (4) has an energy level close to midgap $\left(E_{c}-0.41 \mathrm{eV}\right){ }^{8}$ which follows that nearly all substitutional iron are negatively charged in highly phosphorus doped silicon. Note that the exact energy level of the substitutional iron does not significantly affect our simulations as long as the Fermi level is above the energy level of doubly charged vacancies $\left[E_{c}-0.11 \mathrm{eV}\right.$ (Ref. 5)]. The second natural reaction that follows is then

$$
\mathrm{Fe}_{s}{ }^{-}+\mathrm{P}^{+} \leftrightarrow \mathrm{Fe}_{s} \mathrm{P}
$$

where negatively charged substitutional iron forms a pair with positively charged phosphorus. The equilibrium constant in this reaction is characterized as $K_{\text {eq2 }}$. Combining the reactions (4) and (5) and making relatively simple algebraic calculations we get total iron concentration as a function of position in the PDG layer,

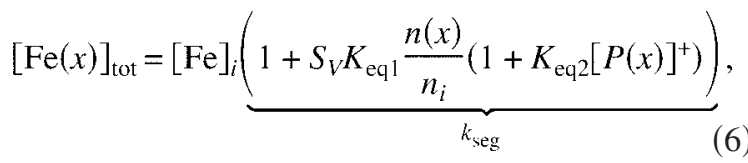

where the part in the parentheses represents the segregation coefficient, which is a function of electron concentration $n$, solubility (or supersaturation) of vacancies $S_{V}$, electrically active phosphorus concentration $\mathrm{P}^{+}$, and intrinsic carrier concentration $n_{i}$.

Note that Eq. (6) does not take into account the exact concentration of neutral and/or single negatively charged vacancies, yet it is valid also in low-doped $n$ - and $p$-Si, where the general assumption is that iron is mainly in the interstitial site in intrinsic silicon ${ }^{8}$ as long as the product $K_{\text {eq } 1} S_{V} \ll 1$ when $[\mathrm{P}]=0$ and $n=n_{i}$. Thus, in fitting we have assumed $K_{\text {eq } 1} S_{V}$ to be constant $\left(1 \times 10^{-5}\right)$, i.e., the activation energy of vacancies and binding energy of substitutional iron compensate each other. The only parameter that remains to be fitted is $K_{\text {eq2}}$.

Possibilities for several other defect reactions between iron and vacancies have been studied in the literature. ${ }^{8}$ Some experimental results support the formation of various phosphorus-iron complexes in $n$-Si in the case of excess vacancies. ${ }^{9}$ Mchedlidze and Kittler also speculated that an injection of vacancies might have an effect on the PDG efficiency ${ }^{9}$ which is in line with our model. Estreicher et al. proposed that $\mathrm{SiN}$ firing (hydrogen passivation of iron) might be actually related to injection of vacancies (vacancy passivation). ${ }^{8}$ Thus, the segregation coefficient can be derived using different reactions than presented here. Note that it is evident that a very similar form for segregation coefficient than Eq. (6) could be found despite which physical reactions are taken into account.

\section{RESULTS AND DISCUSSION}

The segregation coefficient of Eq. (6) is inserted into Eq. (3) resulting in one fitting parameter, the equilibrium constants $K_{\text {eq2 }}$. All the other parameters such as $n_{i}$ and $\mathrm{P}^{+}$are calculated as presented in Ref. 5. Figure 1 shows the fitting results in various temperatures as a form of Arrhenius plot. From the figure we can get the following values for the $K_{\text {eq2 }}$ : $1.7 \times 10^{19} \exp (1.4 \mathrm{eV} / \mathrm{kT})$. These values are obtained by the least squares fitting to all data points. However, it is evident from Fig. 1 that more experimental results are needed to temperatures below $800{ }^{\circ} \mathrm{C}$ for getting more accurate values for $K_{\text {eq2 }}$. In addition, the binding energy of $1.4 \mathrm{eV}$ for the $\mathrm{Fe}_{s} \mathrm{P}$ pair should be considered as an effective value due to the assumption of constant $K_{\text {eq } 1} S_{V}$. This explains the ob- 


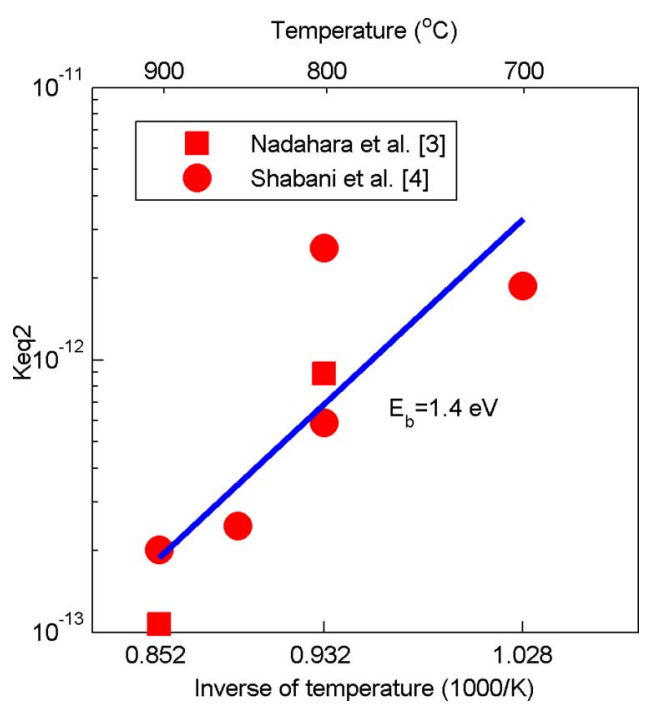

FIG. 1. (Color online) Fitting of equilibrium constant $K_{\text {eq2 }}$ to literature data The symbols show the $K_{\text {eq } 2}$ values fitted to experimental results of Nadahara et al. (Ref. 3) (squares) and Shabani et al. (Ref. 4) (circles).

tained effective binding energy of $1.4 \mathrm{eV}$ which sounds a rather high value when compared to e.g., a binding energy of $\mathrm{Fe}_{i} \mathrm{~B}$ pair $(0.68 \mathrm{eV}){ }^{8}$

Now that we have a "universal" segregation coefficient that depends only on the phosphorus concentration, we can simulate the time dependent PDG efficiency. Figure 2 shows a comparison of experimental and simulations of PDG gettering efficiency of iron as a function of gettering time. The lines in Fig. 2 are calculated using fitted values from Fig. 1. Dashed lines are obtained by simulating phosphorus diffusion and calculating gettering efficiency using Eqs. (6) and (3). Full lines are obtained when both phosphorus and iron diffusion are taken into account. The difference between the lines shows that the time evolution of the iron profile during the anneal has to be taken into account especially at short annealing times. However, after long annealing times the as-

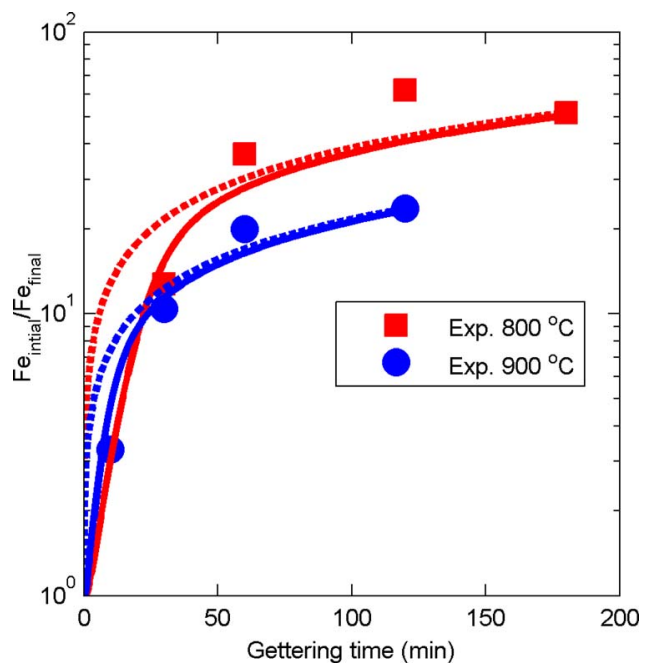

FIG. 2. (Color online) PDG efficiency as a function of gettering time at 800 and $900{ }^{\circ} \mathrm{C}$. Experimental data points are taken from Ref. 3. Dashed line shows the simulation when constant supersaturation is assumed. Full line shows simulation results when both phosphorus and iron diffusions are taken into account.

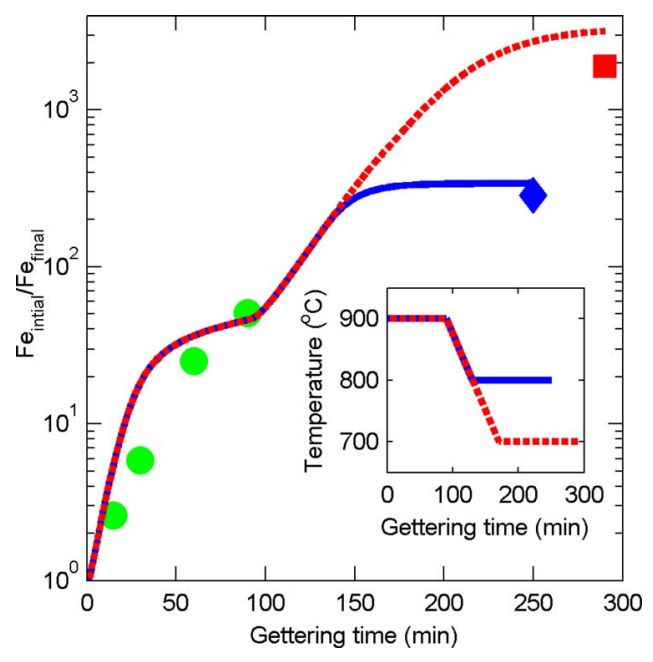

FIG. 3. (Color online) PDG efficiency of iron during low-temperature gettering anneals. Experimental data points are taken from Ref. 4. First $90 \mathrm{~min}$ are annealed at $900{ }^{\circ} \mathrm{C}$, which follows a ramp down to $700{ }^{\circ} \mathrm{C}$ (red line) or $800{ }^{\circ} \mathrm{C}$ (blue line). Inserted figure shows the corresponding temperature time profile.

sumption of constant supersaturation of iron at given temperature seems to be adequate. We have also checked by simulations that the air cooling rate is high enough so that segregation during cooling can be omitted at temperatures of $900{ }^{\circ} \mathrm{C}$ and below when the fitting is done using measured bulk iron concentrations.

It is well expected that with lower temperatures, as the segregation coefficient becomes higher, the PDG efficiency increases. This is also demonstrated by Shabani $e t$ al. ${ }^{4}$ Figure 3 shows our simulation results during low-temperature anneals $\left(K_{\text {eq2 }}\right.$ is calculated using a fitted line in Fig. 1), which shows that our model is in good agreement with experiments at temperatures above $700{ }^{\circ} \mathrm{C}$. Because we have made the fitting at temperatures above $700{ }^{\circ} \mathrm{C}$, we cannot expect quantitative results at temperatures below this.

Besides segregation, the phosphorus doping must affect the diffusivity of iron in $n$-Si. In the above simulations we have assumed the same diffusivity, $D_{i}=10^{-3} \exp ($ $-0.67 \mathrm{eV} / \mathrm{kT}$ ) (Ref. 10) for iron both in the bulk and in the phosphorus layer. However, use of minimum possible effective diffusivity $\left(D_{\text {eff }}=D_{i} / k_{\text {seg }}\right)$, i.e., assuming immobile $\mathrm{Fe}_{s}$, did not have an impact on the simulation results. This can be explained by the fact that the thickness of the gettering layer is in the order of $500 \mathrm{~nm}$ while the total wafer thickness is in the order of $500 \mu \mathrm{m}$. Even with highly decreased diffusivity in phosphorus layer, the diffusion through bulk remains the limiting factor in the gettering process. However, the effective diffusivity is an important parameter as it affects the iron precipitation behavior in the phosphorus layer. ${ }^{11}$

We have analyzed also the result of Gilles et al., ${ }^{12}$ who measured iron solubility in both highly phosphorus doped and low phosphorus doped wafer at $700{ }^{\circ} \mathrm{C}$. Based on their results we get a segregation coefficient of 1200 , which is two orders of magnitude smaller than calculated by Eq. (6) using fitted values for $K_{\text {eq2}}$. The possible explanation to the disagreement could be a difference in vacancy concentration between PDG and the experimental conditions of Gilles et 
al. if we consider only a model presented here. On the other hand, the possible gettering effect of phosphorus precipitates, which is proposed to be the main reason for gettering in Ref. 13, could also explain the apparent disagreement.

\section{CONCLUSIONS}

We have proposed a model for the segregation coefficient for iron in heavily doped phosphorus silicon and during PDG. The physical background, i.e., reaction of interstitial iron with vacancies, of the proposed model is very closely linked to the recently published model for phosphorus diffusion by Benzen et $a l^{5}$ and ab initio calculations of iron reactions ${ }^{8}$ with pre-existing vacancies. The proposed physics behind our model, however, needs further examination and experimental evidence. Nonetheless, we have shown that quantitative modeling of the PDG behavior of iron in silicon at temperatures above $700{ }^{\circ} \mathrm{C}$ is possible. Further we have shown that a fitting procedure described here can be used to fit any physical or experimental model for iron segregation coefficient during PDG.

\section{ACKNOWLEDGMENTS}

The authors are grateful for Dr. M. Shabani from Sumco for providing the details of the experiments. O. Anttila from Bullen Semiconductor Corp. is acknowledged for helpful discussion. The financial support from Endeas Oy, Okmetic Oyj, Semilab Inc., VTI Technologies Oy, TEKES, and Academy of Finland is acknowledged.

${ }^{1}$ A. A. Istratov, W. Huber, and E. R. Weber, J. Electrochem. Soc. 150, G244 (2003).

${ }^{2}$ M. Seibt, A. Sattler, C. Rudolf, O. Voß, V. Kveder, and W. Schröter, Phys. Status Solidi A 203, 696 (2006).

${ }^{3}$ S. Nadahara, H. Tsunoda, M. Shiozaki, M. Watanabe, and K. Yamabe, in Defects in Silicon II, Proceedings of the Second Symposium on Defects in Silicon, Washington, DC, edited by W. M. Bullis and U. Gosele (Electrochemical Society, Pennington, NJ, 1991), pp. 667-674.

${ }^{4}$ M. B. Shabani, T. Yamashita, and E. Morita, Solid State Phenom. 131133, 399 (2008)

${ }^{5}$ A. Bentzen, A. Holt, J. S. Christensen, and B. G. Svensson, J. Appl. Phys. 99, 064502 (2006).

${ }^{6}$ H. Hieslmair, A. A. Istratov, and E. R. Weber, Semicond. Sci. Technol. 16, 567 (2001)

${ }^{7}$ M. Sanati, N. Gonzalez Szwacki, and S. K. Estreicher, Phys. Rev. B 76, 125204 (2007)

${ }^{8}$ S. Estreicher, M. Sanati, and N. Gonzalez Szwacki, Phys. Rev. B 77, 125214 (2008).

${ }^{9}$ T. Mchedlidze and M. Kittler, Phys. Status Solidi A 203, 786 (2006).

${ }^{10}$ A. A. Istratov, H. Hieslmair, and E. R. Weber, Appl. Phys. A: Mater. Sci. Process. 69, 13 (1999).

${ }^{11}$ A. Haarahiltunen, H. Talvitie, H. Savin, M. Yli-Koski, M. I. Asghar, and J. Sinkkonen, Appl. Phys. Lett. 92, 021902 (2008).

${ }^{12}$ D. Gilles, W. Schroter, and W. Bergholz, Phys. Rev. B 41, 5770 (1990).

${ }^{13}$ A. Cuevas, D. Macdonald, M. Kerr, C. Samundsett, A. Sloan, S. Shea, A. Leo, M. Mrcarica, and S. Winderbaum, Conference Record of the 28th IEEE Photovoltaic Specialists Conference, 2000 (unpublished), pp. 244247 